\title{
A LONGEVITY RECORD FOR CANADA LYNX, LYNX CANADENSIS, IN WESTERN MONTANA
}

\author{
Jay A. Kolbe ${ }^{1,2}$ and John R. Squires ${ }^{1}$
}

Key words: Canada lynx, Lynx canadensis, longevity, demography.

The Canada lynx (Lynx canadensis) was listed as a threatened species under the Endangered Species Act (USDI Fish and Wildlife Service 2000) in 2000 and is a species of conservation concern in the United States. New insights into the basic demography of southern lynx populations are needed. Data describing population age structures, including maximum ages, will allow biologists to better evaluate how well spatially isolated lynx populations can withstand cyclic or stochastic environmental variations, which may temporarily depress reproduction. Longevity data may also allow researchers to determine the probability that lynx will successfully recolonize unoccupied habitat patches.

Little is known about the maximum ages of lynx in the United States. Lynx can be assigned to broad age classes based on morphological characteristics (Saunders 1964, Ward and Krebs 1985, Koehler 1990). However, counts of cementum annuli in teeth yield more specific ages (Brand and Keith 1979, Parker et al. 1983, Quinn and Thompson 1987, Chubbs and Phillips 1993). Parker et al. (1983) reported 11-year-old lynx on Cape Brenton Island, and Quinn and Thompson (1987) documented a female lynx in northeastern Ontario that reached age 13. Prior to the observation we report herein, the wild-born lynx longevity record was held by a 14-year-old female caught by a fur trapper in south central Labrador (Chubbs and Phillips 1993).

We captured and radio-collared a male lynx (designated M101) in the Garnet Mountains $\left(46^{\circ} 54^{\prime} \mathrm{N}, 113^{\circ} 15^{\prime} \mathrm{W}\right)$ of west central Montana in mid-February 2003. We noted that his teeth were very worn and stained but that he was in good overall condition. During the late-Febru- ary breeding season, M101 paired with a resident radio-collared female that birthed a litter of kittens in early summer 2003. This female died in January 2004, and we did not observe another female within M101's home range that winter. M101 died on 15 June 2004. Trauma to his head and the scat found at the site indicated that he had been killed by a mountain lion (Puma concolor).

We extracted and aged a canine tooth using a cementum annuli count (Matson's Laboratory, Milltown, MT). M101's age was reliably determined to be 16 years $(>95 \%$ expected accuracy; Matson 1981; Fig. 1). This is the longest lived, wild-born Canada lynx reported in the literature. This animal lived in a small, geographically isolated mountain range more than $35 \mathrm{~km}$ from the nearest known occupied lynx habitat; he was apparently reproductively active until at least 15 years of age.

This work was funded by the USDA Forest Service, Rocky Mountain Research Station; Federal Highways Administration; Idaho Department of Transportation; USDA Forest Service, Clearwater National Forest; and USDI Bureau of Land Management.

\section{Literature Cited}

BRAND, C.J., AND L.B. Keith. 1979. Lynx demography during a snowshoe hare decline in Alberta. Journal of Wildlife Management 43:827-849.

Chubbs, T.E., And F.R. Phillips. 1993. An apparent longevity record for Canada lynx, Lynx canadensis, in Labrador. Canadian Field Naturalist 107:367-368.

Koehler, G.M. 1990. Population and habitat characteristics of lynx and snowshoe hares in north central Washington. Canadian Journal of Zoology 68:845-851.

Matson, G.M. 1981. Workbook for cementum analysis. Matson’s Laboratory, Milltown, MT. 30 pp.

${ }^{1}$ USDA Forest Service, Rocky Mountain Research Station, Box 8089, Missoula, MT 59807.

${ }^{2}$ E-mail: jaykolbe@hotmail.com 


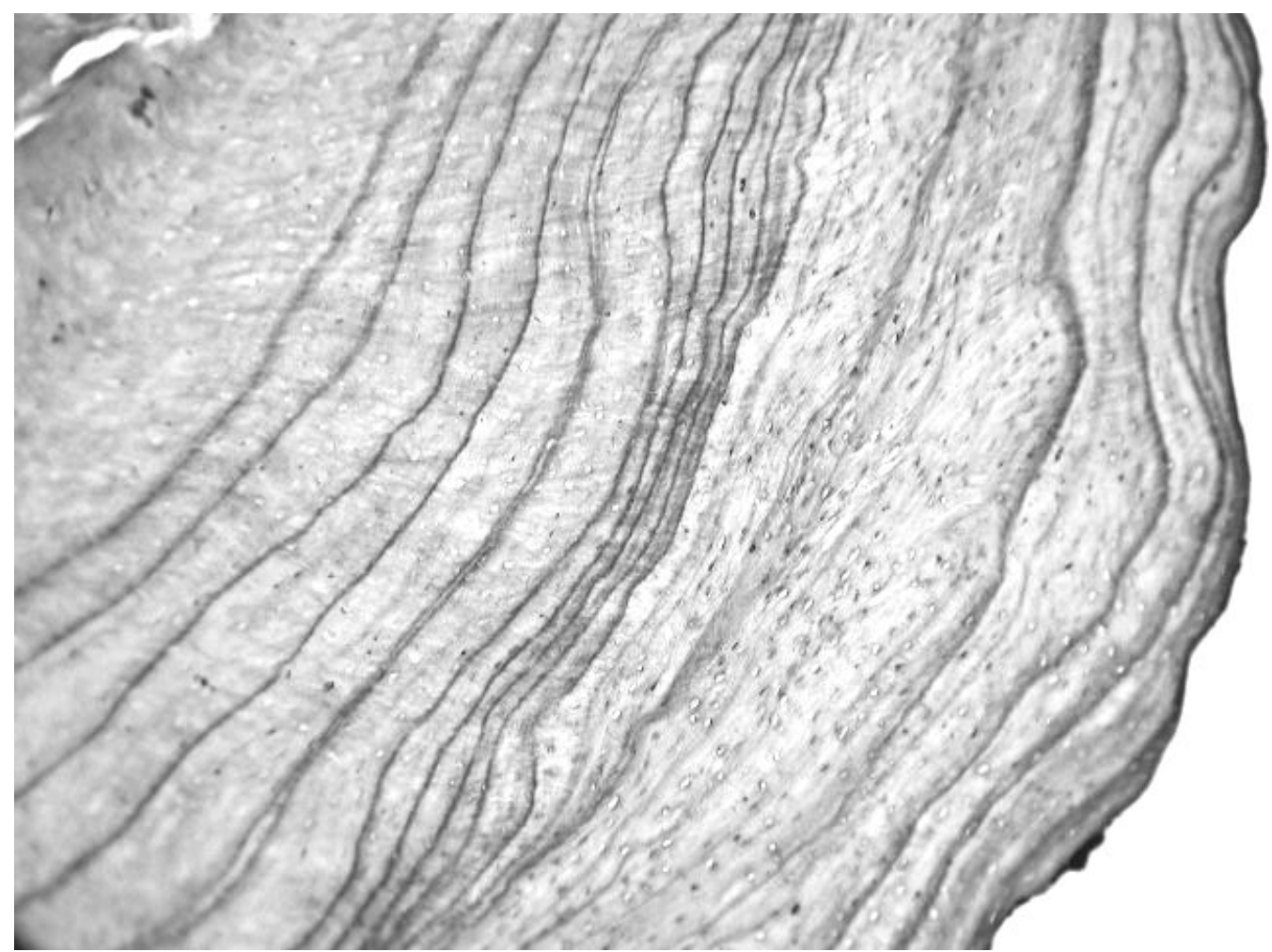

Fig. 1. A photomicrograph of the cementum annuli (canine tooth) of Canada lynx M101, which died in western Montana in June 2004. There are 15 distinct annuli; the last one is at the periphery of the root. For lynx, the 1st annulus, which is well separated from the junction at the root tip, is formed during the 2 nd winter of life. The age at death was 16 years (>95\% expected accuracy; Matson’s Laboratory, Milltown, MT).

Parker, G.R., J.W. Maxwell, L.D. Morton, and G.E. SMITH. 1983. The ecology of the lynx on Cape Brenton Island. Canadian Journal of Zoology 61:770-786.

Quinn, N.W.S., AND J.E. Thompson. 1987. Dynamics of an exploited Canada lynx population in Ontario. Journal of Wildlife Management 51:297-305.

Saunders, J.K. 1964. Physical characteristics of the Newfoundland lynx. Journal of Mammalogy 45:36-47.

USDI Fish and Wildlife Service. 2000. Endangered and threatened wildlife and plants; determination of threatened status for the contiguous U.S. distinct population segment of the Canada Lynx and related rule. Federal Register 65(58):16051-16086.

WARD, R.M.P., AND C.J. KREBS. 1985. Behavioural responses of lynx to declining snowshoe hare abundance. Canadian Journal of Zoology 63:2817-2824.

Received 30 August 2005 Accepted 12 April 2006 